\title{
МЕДИАОБРАЗОВАНИЕ В УСЛОВИЯХ ЦИФРОВИЗАЦИИ ОБЩЕСТВА
}

\author{
В.Г. Мамчук \\ Московский гуманитарный университет
}

Аннотация: В статье анализируется актуальность потребности современного студента в медиаобразовании. Рассматриваются оптимальные варианты включения медиаграмотности в программу высшего учебного заведения с учетом максимального охвата аудитории при отсутствии дополнительной нагрузки.

Ключевые слова: иифровое общество; медиаграмотность; медиаобразование; медиа; элективный курс; факультативный курс; интеграционный подход

\section{MEDIA EDUCATION IN THE CONTEXT OF A DIGITAL SOCIETY.}

\author{
V.G. Mamchuk \\ Moscow University for the Humanities
}

\begin{abstract}
The article analyzes the relevance of a modern student's needs in media education. Author considers possible options for including media literacy in the curriculum of Russian higher educational institutions.

Keywords: digital society; media literacy; media education; media; elective course; optional course; integration approach
\end{abstract}

Принято считать, что развитие цифровых технологий оказывает главным образом положительное влияние на современное общество, в особенности на представителей младшего поколения, обучающихся в школах и вузах, т.к. оно позволяет значительно облегчить и ускорить процесс обучения.

Так, представители современного студенчества имеют неоспоримое преимущество по сравнению с их предшественниками, а именно беспрепятственный доступ к большей части информационных источников со всей планеты. В наши дни любой заинтересованный человек может ознакомиться с отсканированными копиями средневековых источников. При этом, не выходя из дома, каждый из нас может ознакомиться с экспозициями старейших музеев и библиотек мира при помощи услуги «виртуального тура». Из этого следует, что в наше время перед каждым студентом открываются неограниченные возможности для развития личности и интеллекта, обновления и дополнения имеющихся знаний при помощи материалов, предоставляемых медиа. Однако существует ряд отрицательных факторов, оказывающих негативное влияние на современную молодёжь и не позволяющих согласиться с данной позицией.

Одним из примеров негативного влияния медиа может послужить анализ результатов исследования, опубликованного в 2015 г. Организацией экономического сотрудничества и развития (ОЭСР). Полученные данные обнаруживают прямую зависимость между частотой применения компьютерных 
технологий в образовательных целях и успеваемостью обучающихся. Успеваемость обучающихся, использующих компьютеры в образовательных целях на регулярной основе, оказалась значительно ниже успеваемости их коллег, использующих компьютеры более редко (Уокер, 2018).

Важной проблемой является и то, что современные студенты, подбирая необходимую для занятий информацию в интернете, чаще всего, слепо полагаются на данные, предлагаемые ресурсом. Более того, они считают, что сделанный ими выбор является осознанным и самостоятельным.

Активное внедрение таргетированной рекламы привело к возникновению особых алгоритмов, отслеживающих поисковые запросы каждого пользователя и предлагающих информацию, которая, теоретически, могла бы его заинтересовать. Однако не только целевая реклама позволяет выявить интересы молодежи. Исследования психологов и социологов также позволяют представителям индустрии развлечений создать информационный или физический продукт, способный привлечь внимание максимального количества представителей целевой аудитории и, как результат, принести компании как можно большую прибыль. Такая ситуация, несомненно, вызывает опасения, поскольку влияние, оказываемое современными технологиями на ещё не сформированную психику подростков, может оказаться критическим в виду отсутствия у них богатого жизненного опыта и навыка критического мышления, позволяющего противостоять различным манипуляциям и иным способам воздействия на психику человека.

Одним из примеров позитивного влияния цифровых технологий на образовательный процесс можно считать уроки медиа-безопасности, предложенные к проведению в ряде российских образовательных учреждений в 2011 г. П.А. Астаховым, занимавшим пост Уполномоченного при президенте Российской Федерации по правам ребёнка. Так 1 сентября в российских школах состоялись уроки, проинформировавшие детей об основных правилах поведения во время использования сети интернет. Успех проведенных мероприятий привел к разработке Астаховым отдельного курса, посвященного проблеме медиабезопасности среди детей и подростков (Симакова, 2013).

Применение цифровых технологий в образовании имело большой успех у самих обучающихся прежде всего потому, что это привнесло элементы игровой и исследовательской деятельности в рутинные процессы. Тем не менее, нельзя полностью полагаться на интернет и различные устройства до тех пор, пока обучающиеся не будут способны грамотно отбирать, анализировать и применять полученную информацию.

Из этого следует, что в наши дни формирование медиа-грамотности является первостепенной задачей вуза для эффективного и здорового функционирования обучающихся в условиях цифрового общества, сопровождаемого различными 
Научные труды Московского гуманитарного университета

2020 № 6

кризисными ситуациями, в том числе, политического и экономического характера.

Говоря о современном образовании, профессор Мальтийского университета К. Борг в одной из своих работ ссылается на высказывание педагога Барбианской школы Дона Лоренцо Милани, считавшего, что изначально несправедливые условия, созданные в образовательных учреждениях, порой вынуждают педагога идти против системы, ведя «незаметную, но порой даже тайную работу, направленную на изменение сложившейся ситуации» (Борг, 2016). Рост популярности неолиберальных взглядов позволил исключить фактор «тайной работы», дав педагогам возможность открыто выражать собственную позицию относительно положения современной системы образования, и вносить предложения по данной проблематике. Одним из злободневных нововведений остается необходимость внедрения медиа-образования в образовательный процесс.

Борг продолжает дискуссию, приводя в пример позиции других зарубежных коллег: «Как показали Дьюи и Ноддингс (Dewey, 1916; Noddings, 2011), совершенно неправомерно утверждать, что одна область знания более интеллектуально насыщена, чем другая. Мы должны расширять, а не сокращать программу образования, иначе наши представления об образовании станут слишком узкими, и, соответственно, не будут служить интересам образования» (Борг, 2016). Логично, что в условиях новых вызовов современности, работа педагога включает в себя не только необходимость качественного обучения своему предмету, но и подготовку обучающихся к столкновениям с угрозами, скрывающимися как в реальном мире, так и в медиапространстве.

На первый план выходят такие умения и навыки, как способность быстро ориентироваться в большом объеме малознакомых данных, умение выделять основные моменты и оперировать ими, подвергать их критической оценке, и, наконец, делать собственные умозаключения на основе обработанной информации, моральных ценностей и жизненного опыта обучающегося. Актуальность этих навыков в массовом ключе представляет гораздо большую ценность, нежели знание теоремы Виета или умение решать химические задачи, т.к., в виду непрерывного взаимодействия современного человека с медиа, они будут гораздо чаще применяться обучающимися на практике.

Для формирования навыка медиаграмотности (медиакомпетентности) у студентов можно воспользоваться несколькими опциями: создать спецкурс, например, элективный, факультативный курс, или же обратиться к интегративному методу, включив в традиционный предмет базовой программы элементы медиаобразования, например, посредством их внедрения в процесс преподавания иностранного языка. Интеграция медиаобразования в уже имеющиеся предметы позволит не только изучить конкретный предмет в рамках рабочей программы дисциплины, но и углубить знания, выйдя за ее пределы.

Вчемжеразницамеждуданнымиопциями?Какойизвариантовбудетнаиболее 
благоприятным и эффективным при формировании медиакомпетентности у студентов гуманитарных вузов в процессе изучения иностранного языка? Представленные варианты имеют существенные различия. Рассмотрим разницу между элективным и факультативным курсами. Первый, как правило, подразумевает обязательный характер посещения для всех обучающихся, второй же, напротив, носит рекомендательный характер и не является обязательным для посещения. Вариативность доступных элективных курсов позволяет широко применять индивидуальный подход к обучению, давая студенту выбор относительно присоединения к наиболее интересному и полезному для будущей сферы занятости курсу. Учитывая тот факт, что медиаобразование не является обязательным компонентом образовательной программы на территории Российской Федерации, организация элективных курсов по иностранному языку является актуальным, перспективным и относительно легко реализуемым способом развития медиаграмотности у студентов гуманитарных направлений.

Однако нельзя не принять во внимание уже имеющийся большой объем учебной нагрузки. Из этого следует, что элективный или факультативный курс нельзя считать наиболее удобным и перспективным инструментом формирования медиакомпетентности студентов в силу изначально высокого уровня имеющейся нагрузки. Более того, выборный характер курса не позволит вузу охватить всю студенческую аудиторию, препятствуя массовости обучения медиаграмотности.

Таким образом, интеграция медиаобразования в уже имеющийся предмет, охватывающий студентов всех факультетов вуза, является наиболее перспективной и приемлемой опцией. Ориентируясь на опыт зарубежных коллег, российские медиапедагоги постепенно начинают внедрять материалы, представленные в средствах массовой коммуникации (СМК) в образовательный процесс как в школах, так и в вузах. Не следует упускать из вида факт, что используемые материалы будут повышать эффективность обучения лишь при их верном подборе в соответствии с тематикой основной программы, учете актуальности используемых СМК и положительном влиянии предложенных дополнительных материалов на уровень заинтересованности и вовлеченности обучающихся в предмет (Никитина, 2015). Л.С. Зазнобина отмечает, что главным содержанием интеграционного подхода к медиаобразованию является «интеллектуальное и процессуальное умение информационного взаимодействия» (Зазнобина, 1998). Нельзя не согласиться и с позицией А.В. Спичкина, заявляющего, что основными трудностями, связанными с интеграцией медиаобразования в процесс преподавания дисциплин базового блока, является поиск элементов, связывающих этот предмет с медиаобразованием, а также процесс непосредственной координации программ дисциплин (Спичкин, 1999).

Учитывая наличие в высших учебных заведениях специально утвержденного учебного плана, не включающего в себя медиаобразование какотдельный предмет, 
а также нежелательную для студентов нагрузку со стороны дополнительных элективных и факультативных курсов, неспособных обеспечить полноценный и равномерный охват аудитории вуза, наиболее целесообразным вариантом развития медиаграмотности студентов, на наш взгляд, является включение элементов медиаобразования в предметы базового блока дисциплин с учетом сопоставимости целей медиаобразования со знаниями, навыками и умениями, приобретаемыми в процессе изучения уже сформированного курса традиционной дисциплины.

Последовательный характер внедрения медиаобразования в уже существующий курс, преследующий своей целью воспитать медиаграмотное поколение, позволит педагогам рассчитывать на то, что выпускники их вуза будут отличаться высоким уровнем медиаграмотности как в процессе дальнейшего обучения, так и в профессиональной деятельности, что даст им неоспоримое преимущество на рынке труда.

Рассмотрев вышеуказанные преимущества и недостатки представленных методов формирования медиаграмотности на базе вузов, можно сделать вывод, что интеграционный подход в целом и внедрение медиаобразования в преподавание иностранного языка в частности является наиболее удачным подходом к реализации медиаобразования в рамках современной образовательной системы с учетом непрерывного повышения учебной нагрузки, а также массового характера распределения информации в рядах аудитории вуза.

\section{СПИСОК ЛИТЕРАТУРЫ}

Борг К. (2016) Общественный класс, язык и власть. Письмо к учительнице: Лоренцо Милани и Барбианская школа // Борг К., Кардона М., Каруана С. СПб.: Александрия. С. 288-291.

Зазнобина Л.С. (1988) Стандарт медиаобразования, интегрированного с различными школьными дисциплинами //Стандарты и мониторинг в образовании. № 3. С. 26-34.

Никитина Е.Ю. (2015) Формирование медиакомпетенции младших школьников на уроках русского языка // Никитина Е.Ю., Милютина А.А. М: Перо. С. 108.

Симакова С.И. (2013) Формирование медиакомпетентности в системе вузовского образования //Вестник Челябинского государственного университета. № 22 (313). Филология. Искусствоведение. Вып. 81. С. 58.

Спичкин А.В. (1999) Что такое медиаобразование. Курган. 114 с.

Уокер Т. (2018) Финская система обучения. Как устроены лучшие школы в мире. М.: Альпина Паблишер. С. 191.

Мамчук Валерия Геннадьевна - магистрант 3 курса кафедры педагогики и психологии высшей школы Московского гуманитарного университета. Научный 
руководитель - д-р пед. н., профессор В.А. Ситаров. Адрес: 111395, Россия, г. Москва, ул. Юности, д. 5. Тел.: +7 (499) 374-74-59. Эл. адрес: vmamchuk@mosgu.ru Mamchuk Valeria Gennadevjna, Graduate Student, Department of Pedagogy and Psychology of Higher Education, Moscow University for the Humanities. Scientific Adviser - V.A. Sitarov, Doctor of Pedagogy, Professor. Postal address: 5, Yunosti Street, Moscow, Russian Federation, 111395. Tel.: +7(499)374-74-59. E-mail: vmamchuk@mosgu.ru. 